\title{
Evaluation of the Hydatid Cyst Membrane Permeability of Albendazole and Albendazole Sulfoxide-Loaded Solid Lipid Nanoparticles
}

\author{
Shahrzad Soltani, ${ }^{1,2}$ Abdollah Rafiei, ${ }^{1,2,}{ }^{*}$ Zahra Ramezani, ${ }^{3}$ Mohammad Reza Abbaspour, ${ }^{4}$ Ali Jelowdar, ${ }^{2}$ \\ and Mehdi Sagha Kahvaz ${ }^{3}$ \\ ${ }^{1}$ Health Reaserch Institute, Infectious and Tropical Diseases Research Center, Jundishapur University of Medical Sciences, Ahvaz, Iran \\ ${ }^{2}$ Department of Parasitology, Medical School, Ahvaz Jundishapur University of Medical Sciences, Ahvaz, Iran \\ ${ }^{3}$ Nanotechnology Research Center, School of Pharmacy, Ahvaz Jundishapur University of Medical Sciences, Ahvaz, Iran \\ ${ }^{4}$ Targeted Drug Delivery Research Center, School of Pharmacy, Mashhad University of Medical Sciences, Mashhad, Iran \\ "Corresponding author: Abdollah Rafiei, Department of Parasitology, Medical School, Ahvaz Jundishapur University of Medical Sciences, Ahvaz, Iran. Tel: +98-613337077, Fax: \\ +98-6133367868, E-mail: rafieiabdollah@yahoo
}

Received 2015 November 16; Revised 2015 November 28; Accepted 2015 December 06.

\begin{abstract}
Background: Albendazole (ABZ) and albendazole sulfoxide (ABZSO) have a basic role in the treatment of hydatid cysts. However, their poor solubility and limited intestinal permeability are the main problems in their formulation.

Objectives: The preparation and characterization of ABZ and ABZSO-loaded solid lipid nanoparticles (SLNs) to increase the hydatid cyst membrane permeation by loading into SLNs.

Materials and Methods: First, ABZ and ABZSO-loaded SLNs were prepared by micro emulsification and high shear homogenization. Physicochemical characterization of the formulations for particle size, polydispersity index, drug entrapment efficiency (EE) and drug loading (DL), zeta potential, particle shape, drug stability, and in vitro drug release studies were evaluated. Next, the permeability of conventional and prepared formulations on hydatid cysts was evaluated by quantifying the drug concentrations in cyst fluid using high-performance liquid chromatography (HPLC).

Results: The prepared formulations showed particle sizes $<180 \mathrm{~nm}$, polydispersity index values around 0.08 with narrow size distributions, a high EE of (91\%) for ABZ-SLN and (94\%) for ABZSO-SLN, and ideal stabilities with regard to their largely negative zeta potentials. The in vitro drug release of free drugs exhibited very fast release in the initial time, but displayed a biphasic pattern for drug-loaded SLNs. Greater permeability was achieved using the SLN preparations.

Conclusions: ABZ and ABZSO achieved good physicochemical characterizations, controlled release, higher permeability and efficacy by loading into SLNs, and are promising for the treatment of this disease.
\end{abstract}

Keywords: Albendazole, Albendazole Sulfoxide, SLNs, Characterization, Permeability, HPLC

\section{Background}

Hydatidosis is a serious health problem in many parts of the world, most commonly in sheep-rearing areas. Approximately $65 \%$ to $70 \%$ of infections occur in the liver, but most organs can be affected $(1,2)$. Three options are recommended for treatment: surgery, puncture-aspiration injection-respiration (PAIR), and chemotherapy. Although surgery is the method of choice, chemotherapy is an important treatment for inoperable cases or in combination with surgery to prevent recurrent infections $(3,4)$. Benzimidazole (BZD) compounds are currently administered to patients exhibiting high surgical risk, and preand post-operative to prevent secondary hydatidosis $(5,6)$. Among BZD compounds, albendazole (ABZ) is the drug of choice for echinococcosis in humans and has been demonstrated to be effective against cystic echinococcosis (CE).
After oral administration, ABZ is metabolized into albendazole sulfoxide (ABZSO) by hepatic enzymes. These anthelmintic compounds inhibit the polymerization of $\beta$ tubulin, which blocks glucose uptake, depletes glycogen, disrupts cell division and, ultimately, results in parasite death (7-9). Hydatid cyst membranes behave like barriers; they consist of one host-derived fibrous layer and two parasite-derived layers that include an external, laminated, a cellular layer (about $1 \mathrm{~mm}$ thick) and a thin, inner, cellular, germinal layer (10 - $25 \mu$ m thick). The germinal layer in fertile cysts has brood capsules and protoscoleces, but infertile cysts have only a germinal layer without protoscoleces (10). The poor solubility and low gastro intestinal (GI) absorption ( $<5 \%$ ) of drugs means that patients of conventional therapy must consume high doses of drugs for a long period. This can cause adverse side- 
effects such as abnormal liver function, leucopenia, and GI problems $(11,12)$. Nano carrier-based drug delivery systems are currently employed to overcome the limitations associated with conventional chemotherapy. These carriers supply the drug for a determined period of time with a controlled dose $(13,14)$. Several nano-carriers, including micelles, liposomes, nano-capsules, and solid lipid nanoparticles (SLNs), have been developed (14-16). SLNs were used as a drug delivery carrier at the beginning of the 1990s (17). They have been also described as a suitable drug delivery system for lipophilic drugs. The main advantage of SLNs is the use of physiological lipid matrices that decrease immune response and toxicity $(18,19)$. These carriers have applications for controlled drug release, increasing drug stability, target ability, enhanced therapeutic efficacy, and reduced erratic absorption (20-25). A high correlation between molecular lipid solubility and the bioavailability of lipophilic drugs has been demonstrated; however, the improved dissolution of drug-loaded nanoparticle dosage forms could increase the bioavailability of poorly soluble drugs (26-29). The present study compared the ability of conventional and SLN forms to diffuse ABZ and ABZSO through the cyst layers of fertile and infertile hydatid cysts. It has been reported that the success rate of chemotherapy in hydatid disease can primarily be attributed to the drug's ability to penetrate the cyst layers and produce an adequate concentration of the drug on the interior agents for a specific period of time (30-32).

\section{Objectives}

The aim of the current study was to design ABZ and ABZSO-loaded SLNs to increase drug permeation across the hydatid cyst membrane and reduce the systemic side effects of conventional drugs. This study evaluated the physicochemical parameters of the drug required to allow good drug diffusion and enhance the drug concentration in a cyst environment to increase the efficacy by loading into SLNs.

\section{Materials and Methods}

\subsection{Materials}

Compritol 888 ATO was gifted from Gattefosse company (France). Polyoxyethylene sorbitan fatty acid ester (Tween 80), polyvinyl alcohol (PVA), and ABZSO were purchased from Sigma-Aldrich. ABZ was kindly supplied by Daroupakhsh pharmaceutical (Tehran, Iran). All other chemicals used were of HPLC grade and were purchased from Sigma chemical(USA). Double distilled and deionized water was used throughout the study.

\subsection{Methods}

\subsubsection{Preparation of SLNS}

The blank and drug-loaded SLNs were prepared using micro emulsification and high shear homogenization methods. Briefly, $7 \mathrm{~g}$ of comprisal 888 ATO was melted by heating it at $75^{\circ} \mathrm{C}$ and $500 \mathrm{mg}$ of the drug (ABZ or ABZSO) was dissolved in the melted lipid. Next, $1 \mathrm{~g}$ of Tween-80 and $1 \mathrm{~g}$ of PVA were dissolved in $100 \mathrm{~mL}$ of deionized water at $80^{\circ} \mathrm{C}$ and mixed at a rate of $500 \mathrm{rpm}$ using a magnetic stirrer (IKA, RHB2, Germany). The lipid phase was then added to the aqueous phase and sonicated in an ultrasonic bath (S $3 \mathrm{OH}$ Elma sonic, Germany) for 5 minutes. The mixture was homogenized at 12,000 rpm for 10 - 15 minutes using a mechanical homogenizer (IKA, T25 digital, ULTRA TURRAX, Germany). The nano emulsion was then added to $100 \mathrm{~mL}$ of cold deionized water $\left(3^{\circ} \mathrm{C}\right)$, mixed for a further $30 \mathrm{~min}$ utes, and centrifuged at 5,000 rpm (by Clements 2,000; Australia) for 4 minutes to remove aggregates and larger particles. The supernatant was separated and centrifuged twice at 30,000 rpm for 30 minutes at $4^{\circ} \mathrm{C}$ using an ultracooling centrifuge (Vision Scientific Co., Ltd. South Korea). The resulting SLNs were freeze-dried after freezing them at $-20^{\circ} \mathrm{C}$ and stored in vials at $4^{\circ} \mathrm{C}$ until use.

\subsubsection{Characterization of Nanoparticles}

\subsubsection{Particle Size and Zeta Potential Determination}

The mean particle size and polydispersity index (PDI) of the sample dispersions were determined by photon correlation spectroscopy using a particle size analyzer (ScatterScope 1 qudix, Korea). The zeta potential of the SLN dispersions was determined using a zeta sizer (Zen 3600; Malvern instruments; UK). The lipid particulate of the dispersion was diluted $(1: 100(\mathrm{v} / \mathrm{v}))$ with double distilled water before the assessments.

\subsubsection{Particle Shape and Surface Morphology}

The shape and the surface morphology of the nano particles were determined using images obtained from an atomic force microscope (AFM) (Nanowizard II; JPK instruments; Germany). The SLN formulations were diluted to 1:10 with distilled water and sonicated for about $30 \mathrm{~min}$ utes in an ultrasonic agitator (UP400S; Hielscher Ultrasonics; Germany). The preparations were then deposited onto a mica sheet and observed under the AFM.

\subsubsection{Measurement of Entrapment Efficiency and Drug-} Loading

SLN suspensions were centrifuged twice at 30,000 rpm for 30 minutes, and $1 \mathrm{~mL}$ of supernatant was analyzed for the free drug using high performance liquid chromatography (HPLC). The entrapment efficiency (EE; \%) and drugloading (DL; \%) were determined as follows: 


$$
\begin{aligned}
E E(\%)= & \frac{\text { Total } \text { drug }- \text { Free } \quad \text { drug }}{\text { Total drug }} \times 100 \\
D L(\%)= & \frac{\text { Total drug }- \text { Free drug }}{\text { Total drug }+ \text { Total lipid }- \text { Free }} \text { drug } \\
& \times 100
\end{aligned}
$$

Where the total drug is the amount of the drug used in the SLN formulation, the free drug is the unloaded drug that presents in the supernatant, and the total lipid is the amount of lipid used in the SLN formulation (33).

\subsubsection{In Vitro Drug Release Study}

The in vitro drug release from SLNs was evaluated using the dialysis membrane method. Dialysis bags (D6191-25EA; MWCO 12,000 Da cut-off; Sigma-Aldrich) were hydrated in phosphate-buffered saline (PBS) at a pH of 7.4 for 24 hour before use. Four bags were prepared containing free $\mathrm{ABZ}$, free ABZSO, ABZ-SLN, and ABZSO-SLN. About $3 \mathrm{~mL}$ of each formulation was placed into a dialysis bag that was tied at both ends and suspended in $25 \mathrm{~mL}$ of PBS (a pH of 7.4) under moderate magnetic stirring at $200 \mathrm{rpm}$ at $37^{\circ} \mathrm{C}$ for 24 hour. Then, $1 \mathrm{~mL}$ samples of the release medium were removed and replaced with fresh buffer in predetermined intervals. The samples were evaluated for their drug content using HPLC.

\subsubsection{Stability Study}

The stability of $5 \mathrm{~mL}$ samples of ABZ-SLN and ABZSO-SLN kept in glass vials at -20 and $4{ }^{\circ} \mathrm{C}$ for 6 months was investigated. The mean particle size, zeta potential, and entrapment efficiency were evaluated after this incubation time (34).

\subsubsection{Hydatid Cyst Membrane Permeation 3.2.5.1. Sample Collection}

Sheep liver hydatid cysts were collected from abattoirs located in the city of Ahvaz in Khuzestan province in southwestern Iran. They were transported to the parasitology laboratory at the department of parasitology, Ahvaz Jundishapur University of Medical Sciences. To study in vitro hydatid cyst membrane permeation, the hydatid cysts were removed from the livers of infected sheep under aseptic conditions and were washed twice with sterile PBS (with a pH of 7.4). The surfaces of the cyst were sterilized using $70 \%$ ethyl alcohol. Their fertility was tested by microscopic examination for the presence of free protoscoleces in cystic fluid $(34,35)$. The cysts were divided into 10 groups of 4 cysts each, as shown in Table 1 . The cysts were maintained in a culture medium (RPMI 1640) containing $25 \%$ fetal calf serum, $0.42 \%$ D-glucose, $0.45 \%$ yeast extract,
$200 \mathrm{u} / \mathrm{mL}$ of penicillin, $200 \mu \mathrm{g} / \mathrm{mL}$ of streptomycin, and 0.5 $\mu \mathrm{g} / \mathrm{mL}$ of amphotericin $\mathrm{B}$ at $37^{\circ} \mathrm{C}$. Then, $2,000 \mu \mathrm{g} / \mathrm{L}$ doses of the free drugs or SLN-loaded drugs were added to the medium (30), and $2 \mathrm{~mL}$ samples of cyst fluid were aspirated from the cysts at 48 hour post-treatment and stored at $-20^{\circ} \mathrm{C}$ prior to the analysis of the permeated drug content using HPLC. Furthermore, to determine the effect of the drug concentration and/or incubation time on drug permeability, some experimental groups were exposed to $2,500 \mu \mathrm{g} / \mathrm{L}$ of the drug, and the concentration of the drug in the cyst fluid was determined after 72 hours of incubation.

\subsection{6. $A B Z$ and $A B Z S O$ Assay \\ 3.2.6.1. Drug Extraction}

Drug extraction co-extracts components that make drug quantification difficult. Briefly, after centrifugation (5,000 rpm, 15 minutes, $4^{\circ} \mathrm{C}$ ), the samples were subject to extraction using acidic denaturation over 30 minutes by adding $500 \mu \mathrm{L}$ of $3 \% \mathrm{HCl}$ to $500 \mu \mathrm{L}$ of the sample with 50 $\mu \mathrm{g} / \mathrm{mL}$ of mebendazole as an internal standard. It was centrifuged at 14,000 rpm for 10 minutes to allow phase separation. The pure supernatant was then transferred to a 5 $\mathrm{mL}$ tube and the solvent was eliminated by evaporation under a stream of nitrogen. The samples were next dissolved in a $1000 \mu \mathrm{L}$ mobile phase, well mixed, and then $50 \mu \mathrm{L}$ of each sample was injected into the HPLC (36). To validate the procedure and quantify the percentage of drugs that can be extracted using this method, determined amounts of the standard drug were added to the cyst fluid and recovered in the same manner as test samples.

\subsubsection{HPLC Method}

The drug concentration was quantified by HPCL (Cecil 1100 series; UK). The mobile phase consisted of acetonitrile double-distilled water adjusted to a $\mathrm{pH}$ of 3.5 using orthophosphoric acid (60:40 (v/v)). A C18 reversed-phase column (H1; Nucleosil 100-5 C18 PAH; UK) with dimensions of $250 \times 4.6 \mathrm{~mm}$ and a packing particle size of $5 \mu \mathrm{m}$ was used. The mobile phase flow rate was set at $1.2 \mathrm{~mL} / \mathrm{min}$. The effluents from the column were detected at $254 \mathrm{~nm}$. About 50 $\mu \mathrm{L}$ of the sample was injected, and the total run time was 30 minutes. The retention time for the ABZ and ABZSO was 3.52 and 4.59 minutes, respectively.

\subsection{Statistical Analysis}

All tests were repeated three times, and the results were presented as mean \pm SD. The statistical evaluations were carried out using one-way ANOVA using SPSS, version 22, software. To indicate the significant differences between treatment groups, Tukey's test was employed as a 


\begin{tabular}{|c|c|c|c|c|c|c|c|}
\hline Group No. & Fertile & Infertile & Control & Treated With Free ABZ & Treated With ABZ-SLN & Treated With Free ABZSO & Treated With ABZSO-SLN \\
\hline $\mathbf{1}$ & $*$ & & * & & & & \\
\hline 2 & $*$ & & & $*$ & & & \\
\hline 3 & $*$ & & & & $*$ & & \\
\hline 4 & $*$ & & & & & * & \\
\hline 5 & $*$ & & & & & & * \\
\hline 6 & & $*$ & * & & & & \\
\hline 7 & & $*$ & & $*$ & & & \\
\hline 8 & & * & & & * & & \\
\hline 9 & & * & & & & * & \\
\hline 10 & & * & & & & & * \\
\hline
\end{tabular}

post-test and the results were considered significant at $\mathrm{P}<$ 0.05 .

\section{Results}

\subsection{Physicochemical Characterization}

Physicochemical characterizations of ABZ-SLN and ABZSO-SLN are presented in Table 2. The mean particle sizes were $<180 \mathrm{~nm}$ and are shown in Figure 1. The PDI were $\sim 0.08$ for both formulations. It has been stated that PDI values of $<0.3$ are considered ideal and indicate a narrow size distribution and that $<0.1$ is considered mono-dispersed. These results indicate that both drugs had narrow size dispersions and were mono-dispersed. The EE was $91 \%$ and $94 \%$ and DL was $6.1 \%$ and $6.34 \%$ for ABZ-SLN and ABZSO-SLN, respectively.

The zeta potential indicates the surface charge and is an important parameter for the stability of the formulation and the prevention of aggregation. Largely negative zeta potentials were obtained for both formulations and indicated their stability. An increase in the zeta potential was observed with ABZSO-SLN (-46.8 mV) over ABZ-SLN ($38.4 \mathrm{mV})$.

\subsubsection{Particle Morphology}

The AFM images of the SLN formulations deposited on mica are shown in Figure 2. All SLN images had a spherical ovoid shape with an average particle size of $163 \mathrm{~nm}$ for ABZSLN and $179 \mathrm{~nm}$ for ABZSO-SLN.

\subsection{In Vitro Drug Release}

The in vitro release behaviors of the free drugs and drug-loaded SLNs were studied by dialysis and the results are presented in Figure 3. Free ABZ and ABZSO released approximately $90 \%$ of the drug within the first half hour; both SLN formulations exhibited a slower release than the free drugs. The percentage of cumulative release over the first half hour was $88.3 \%, 80.5 \%, 38.6 \%$, and $32.1 \%$ for the free ABZ, free ABZSO, ABZ-SLN, and ABZSO-SLN, respectively.

\subsection{Stability}

The stability of the ABZ-SLN and ABZSO-SLN was determined after storage at $-20^{\circ} \mathrm{C}$ and $4^{\circ} \mathrm{C}$ for 6 months, and the results are shown in Table 3. Both SLN formulations showed stability with no significant change in particle size, zeta potential, and $\mathrm{EE}(\mathrm{P}<0.05)$. The stability of the formulations can be attributed to the highly negative charges of the nanoparticles.

\subsection{Permeation Study}

The intra-cystic drug concentrations were evaluated by reverse-phase HPLC to determine the permeation characteristics of all formulations under optimal conditions for separation. Chromatographic peaks were clearly separated from neighboring peaks, and no interference peaks were seen. The linearity of the calibration curves were proven for concentration ranges of 5 to $90 \mu \mathrm{g} / \mathrm{L}$ for ABZ and ABZSO. The correlation coefficient $\left(\mathrm{R}^{2}\right)$ of the calibration curves were 0.9958 for ABZ and 0.9974 for ABZSO, respectively. Drug concentrations were quantified for all experimental groups and the mean \pm SD of results are listed in Table 4, respectively. No drugs were detected in the control groups. The concentrations of ABZ-SLN and ABZSO-SLN in the cyst fluid were significantly greater for all experimental groups over the free suspensions. The results show an increase in drug concentrations in the smaller cysts (0 - 20 $\mathrm{mm}$ ) for both formulations (Figure 4). These results also showed that ABZSO had greater diffusion into the hydatid 
Table 2. The Results of the Characterization of ABZ and ABZSO Solid Lipid Nanoparticles

\begin{tabular}{lcccc}
\hline Drug & Particle Size $(\mathbf{n m})$ & PDI & Zeta Potential (mV) & \% DL \\
\hline ABZ-SLN & 179 & 0.080 & -38.4 & -46.8 \\
ABZSO-SLN & 163 & 0.064 & 91 & 9.1 \\
\hline
\end{tabular}

Figure 1. PSA Graphs of Nanoparticles

A

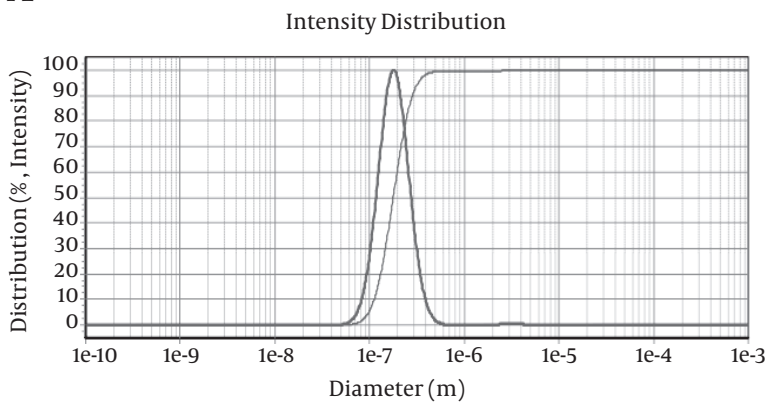

B

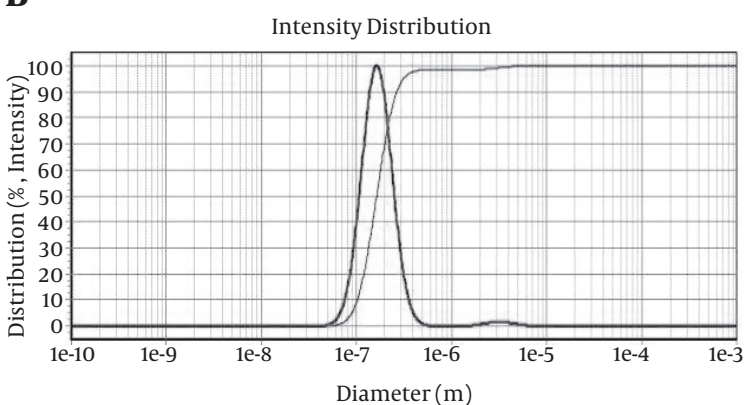

A: ABZ-SLN; B: ABZSO-SLN.

Table 3. The Results of the Stability Tests for ABZ and ABZSO Solid Lipid Nanoparticles After 6 Months

\begin{tabular}{|c|c|c|c|c|c|c|c|c|c|c|}
\hline \multirow[t]{2}{*}{ Drug } & \multicolumn{2}{|c|}{ Particle Size (nm) } & \multicolumn{2}{|c|}{ PDI } & \multicolumn{2}{|c|}{ Zeta Potential $(\mathbf{m V})$} & \multicolumn{2}{|c|}{$\% \mathrm{EE}$} & \multicolumn{2}{|c|}{$\%$ DL } \\
\hline & $-20^{\circ} \mathrm{C}$ & $+4^{\circ} \mathrm{C}$ & $-20^{\circ} \mathrm{C}$ & $+4^{\circ} \mathrm{C}$ & $-20^{\circ} \mathrm{C}$ & $+4^{\circ} \mathrm{C}$ & $-20^{\circ} \mathrm{C}$ & $+4^{\circ} \mathrm{C}$ & $-20^{\circ} \mathrm{C}$ & $+4^{\circ} \mathrm{C}$ \\
\hline ABZ-SLN & 193 & 202 & 0.092 & 0.11 & -32.6 & -30.6 & 88 & 86 & 5.8 & 5.6 \\
\hline ABZSO-SLN & 180 & 191 & 0.083 & 0.094 & -41.5 & -37.8 & 91 & 89 & 6.1 & \\
\hline
\end{tabular}

cyst than did ABZ in both the free and nano forms. Higher concentrations of ABZ and ABZSO were observed in fertile cysts in both the free and nano forms (Figure 4). The highest concentration was obtained for ABZSO-SLN in fertile cysts at 72 hour post-treatment. Increasing the dosages and treatment duration increased the diffusion in all groups.

\section{Discussion}

The management of hydatid disease is challenging, and problems in the treatment of this disease remain unresolved (37). The limitations in surgery indicate that medicinal treatment has frequently been employed alone or in combination with surgery for this disease $(9,38,39)$. The challenge is to increase the effect of chemotherapy by increasing the drug concentrations in the cyst environment using suitable formulations $(30,31,39)$. ABZ is a lipophilic anthelmintic drug for the treatment of echinococcosis in humans. Its active metabolite (ABZSO) has been shown to be an active anthelmintic agent (38). Poor solubility is the main problem in formulations of these compounds; only
$10 \%$ to $20 \%$ of the drug in serum diffuses into the cyst layers. GI mucous behaves like a lipid barrier, and the absorption rate of compounds is based upon their degree of solubility $(27,28,40)$. Nanoparticle drug delivery systems are currently employed to obtain a stable nano-suspension with increases in the drug solubility and dissolution rate $(27,28,41,42)$. Thus this in vitro comparative study was designed to improve the hydatid cyst membrane permeation by loading into SLNs. The micro-emulsification and high shear homogenization methods utilized for the preparation of SLNs in the current study have advantages, such as their simplicity, production of nanoparticles with small particle sizes, low PDI, and high EE. The results show that the average diameters of the nanoparticles were within the nano range of 163 to $179 \mathrm{~nm}$. Previous studies on the mean size of particles have found larger sizes than those in the current study $(31,43)$. The mean particle size is considered to be the most important parameter for improved drug absorption and permeability. Particles with sizes of $<200$ nm usually show increased stability and prolonged circulation; by contrast, particles with sizes of $>200 \mathrm{~nm}$ are rapidly eliminated by the reticule endothelial system and 
A

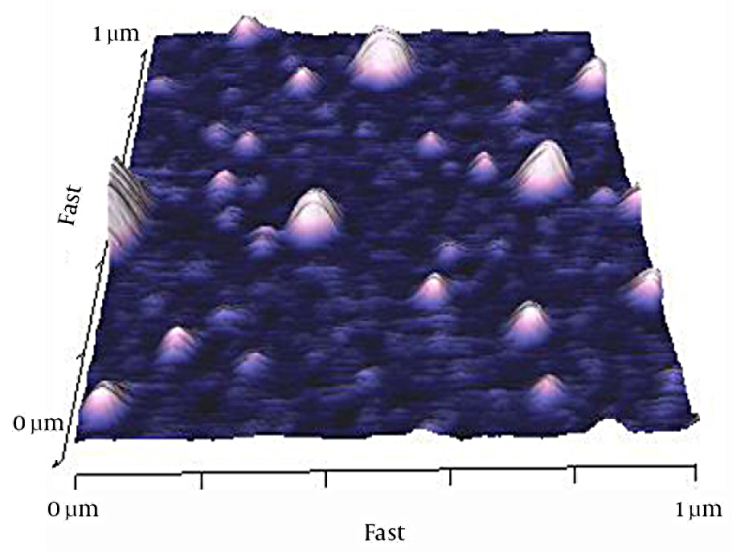

C

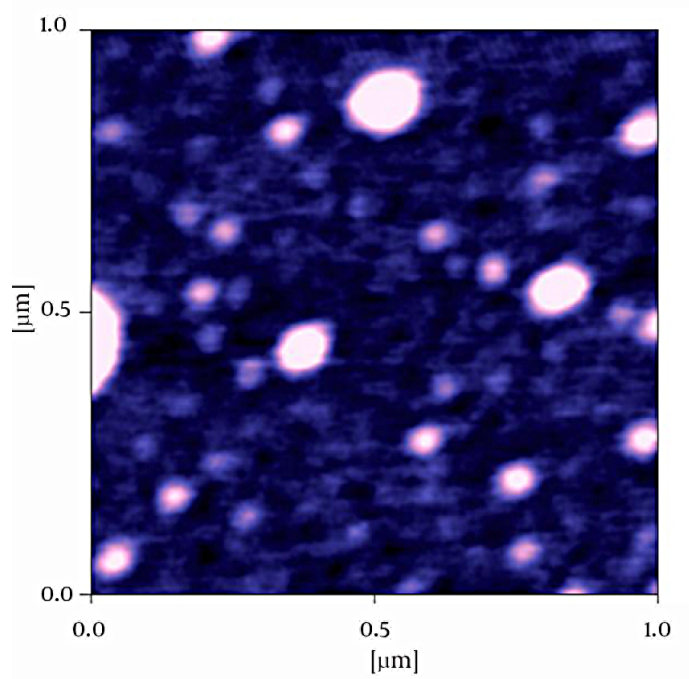

B

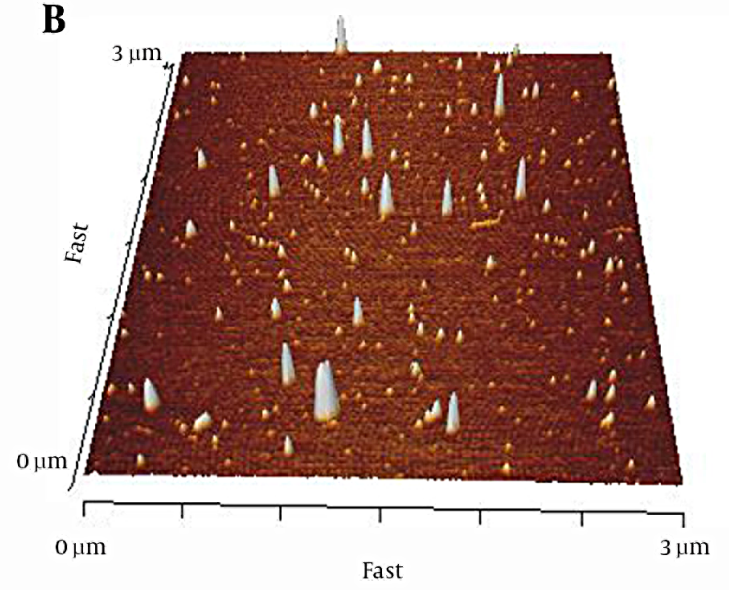

D

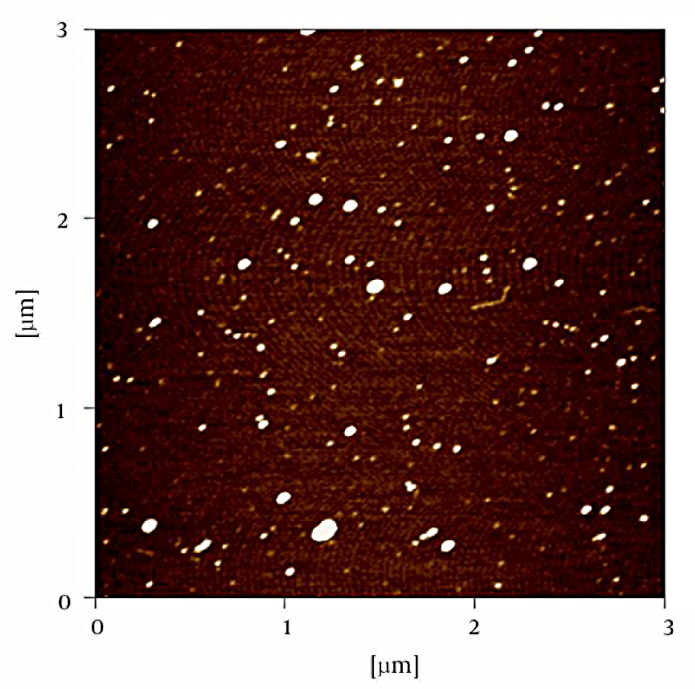

Figure 2. AFM Images of ABZ-SLN (A and C) and ABZSO-SLN (B and D) Formulations

a low percentage could achieve the target site (44). The PDI was $<0.1$ for both drug-loaded SLNs, indicating a very narrow size and mono-dispersed distribution. The zeta potential is the most important factor to affect the stability of the SLN formulations. The zeta potential values in the present study were -38.4 $\mathrm{mV}$ and - $46.8 \mathrm{mV}$ for ABZ-SLN and ABZSO-SLN, respectively. These highly negative charges indicate the stability of SLN formulations. It was demonstrated that negative surface charges with high zeta potential induced by anionic surfactants increased SLN stability and decreased particle aggregation $(31,42)$. The results revealed high EE ( 95\%) for the formulations. Truong Cong et al. (31) prepared ABZ-loaded SLN with $36.4 \% \pm 6.4 \%$ EE. The high EE observed in the present study has not been pro- duced in previous studies using these drugs $(31,43)$. The method, lipid type, surfactant, and ratio of the drug to lipid used could have increased the results for these parameters $(33,45)$. The in vitro release behaviors of the free and nano formulations were compared in the present study. Both free drugs released about 90\% within the first half hour. The drug release profiles for the SLNs were slower than for the free forms and showed a slow release pattern, so that only $38.6 \%$ and $32.1 \%$ of the drug was release in the first half hour from the ABZ-SLN and ABZSO-SLN, respectively. In spite of sustained drug release in SLN formulations, these formulations released their whole drug content within 24 hour. This is in agreement with the results of previous studies $(27,33,46)$. Drug diffusion through 


\begin{tabular}{|c|c|c|c|c|c|c|c|c|c|c|}
\hline \multirow[t]{2}{*}{ Study Groups } & \multirow[t]{2}{*}{ Cyst Size (mm) } & \multirow{2}{*}{$\begin{array}{l}\text { Free/SLN Loaded Drug Conc. in Culture } \\
\text { Medium }^{\mathbf{a}}\end{array}$} & \multicolumn{2}{|c|}{ Free $A B Z^{\mathbf{a}, \mathbf{b}}$} & \multicolumn{2}{|c|}{ ABZ-SLN ${ }^{\mathbf{a}, \mathbf{b}}$} & \multicolumn{2}{|c|}{ Free $\mathbf{A B Z S O}^{\mathbf{a}, \mathbf{b}}$} & \multicolumn{2}{|c|}{ ABZSO-SLN ${ }^{\mathbf{a}, \mathbf{b}}$} \\
\hline & & & After $48 \mathrm{~h}$ & After $72 \mathrm{~h}$ & After $48 \mathrm{~h}$ & After $72 \mathrm{~h}$ & After $48 \mathrm{~h}$ & After $72 \mathrm{~h}$ & After $48 \mathrm{~h}$ & After $72 h$ \\
\hline Control fertile cyst & $20-40$ & 0 & 0 & 0 & 0 & 0 & 0 & 0 & 0 & 0 \\
\hline Fertile cysts & $0-20$ & 2000 & $970 \pm 18$ & $1220 \pm 36$ & $1560 \pm 42$ & $1760 \pm 59$ & $1010 \pm 23$ & $1350 \pm 24$ & $1690 \pm 54$ & $1800 \pm 40$ \\
\hline Fertile cysts & $20-40$ & 2000 & $860 \pm 14$ & ND & & ND & $890 \pm 18$ & ND & $1600 \pm 57$ & ND \\
\hline Control infertile cyst & $20-40$ & 0 & 0 & 0 & & 0 & 0 & 0 & 0 & 0 \\
\hline Infertile cysts & $0-20$ & 2000 & $790 \pm 19$ & $900 \pm 33$ & & $1600 \pm 48$ & $870 \pm 28$ & $1080 \pm 36$ & $1570 \pm 46$ & $1730 \pm 49$ \\
\hline Infertile cysts & $20-40$ & 2000 & $720 \pm 21$ & ND & & ND & $760 \pm 21$ & ND & $1490 \pm 33$ & ND \\
\hline Fertile cysts & $0-20$ & 2500 & $1280 \pm 30$ & $1500 \pm 40$ & & $2080 \pm 55$ & $1360 \pm 43$ & $1650 \pm 45$ & $1950 \pm 47$ & $2340 \pm 35$ \\
\hline Infertile cysts & $0-20$ & 2500 & $1130 \pm 28$ & $1380 \pm 42$ & & $1970 \pm 42$ & $1160 \pm 34$ & $1580 \pm 38$ & $1800 \pm 45$ & $2150 \pm 57$ \\
\hline
\end{tabular}

Abberivation: ND: not determined.

a Value's unit is $\mu \mathrm{g} / \mathrm{L}$.

${ }^{\mathrm{b}}$ Conc. in Cyst Fluid.

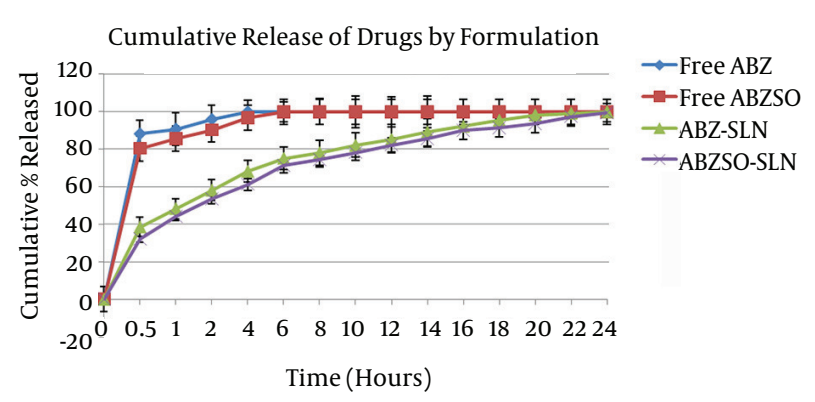

Figure 3. Cumulative Release of Drugs From Free Drug Suspensions or Drug-Loaded SLNs (Mean $\pm \mathrm{SD}$ )

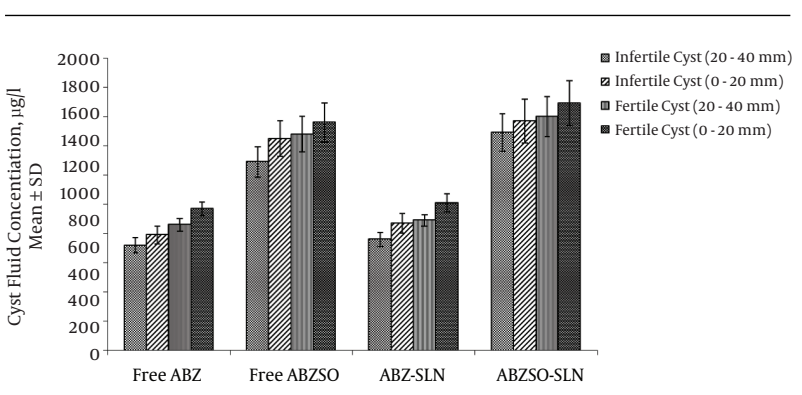

Figure 4. Concentrations of ABZ and ABZSO in Different Groups of Fertile and Infertile Cysts over 48 hour (Mean \pm SD)

the cyst layers was detected in all experimental groups by HPLC. An increase in the drug concentration in the cyst fluid was demonstrated in the groups treated with ABZ-SLN and ABZSO-SLN $(\mathrm{P}<0.05)$ and was probably the result of the better permeability of the nano drugs. Truong Cong et al. (31) used a different methodology and showed that the diffusion of ABZ-SLN from the nanoparticles through the hydatid cyst layer was greater than for free ABZ. Ravichandran (27) reported an improvement using nanoparticles for the increased bioavailability of lipophilic drugs such as ABZ. It was suggested that nanoparticles increased the surface-to-mass ratios more than other particles, increasing the capacity to bind and transfer higher amounts of compounds (47-49). Greater permeability was observed in fertile cysts, even in conventional and nano forms. No data have been found comparing the permeability of drugs into fertile and infertile hydatid cysts. There are structural differences in the germinal layer between fertile and infertile hydatid cysts. This layer greatly affects the permeability of the cysts, and it has been suggested that this structural difference may affect the penetration rate of the drugs $(10,31)$. The present results show a significant correlation between the drug concentration and the size of cysts; smaller cysts showed better permeability for both formulations. Perez-Serrano et al. (50) also reported that BZD performed better protoscolicidal action on young protoscoleces than after they had developed cyst layers. It appears that the major factor affecting the permeability of the drugs is the thickness of the cyst layers; larger forms have thicker layers, which become a thick barrier. The current study compared the permeability of $\mathrm{ABZ}$ and ABZSO into hydatid cysts. The results indicate that ABZSO better diffuses into hydatid cysts than ABZ in both the free and nano forms. No study was found that compared the permeability of ABZ and ABZSO into hydatid cysts. Lanusse et al. (51) reported that ABZSO has greater solubility than other BZDs. It appears that the improved dissolution of drugs increases their diffusion. The results of this study show that ABZ and ABZSO achieved good physicochemical characterizations and controlled release by loading into SLNs. The in vitro permeability study revealed that ABZ-SLN and ABZSO-SLN could significantly enhance the penetration of ABZ and ABZSO into the hydatid cysts; there was also increased permeability into fertile cysts in both conventional and SLNs formulations and higher permeability into 
small cysts. The findings also demonstrate the increased permeability of ABZSO over ABZ. In conclusion, taken together, these results suggested that preparations containing $\mathrm{ABZ}$ and $\mathrm{ABZSO}-$ loaded nanoparticles are promising for the treatment of hydatidosis.

\section{Acknowledgments}

We would like to thank Dr. Teimori and Mr. Noruzi for their assistance. The authors also extend their thanks to the central laboratory of Ahvaz Jundishapur University of Medical Sciences and department of pharmaceutics of the college of pharmacy.

\section{Footnotes}

Authors' Contribution: It is also certified that all authors have participated sufficiently in the work to take public responsibility for the whole content. Each of us has made substantial contributions to the intellectual content of the paper in the conception and design, acquisition of data, analysis and interpretation of data, and drafting and revision of the manuscript.

Funding/Support: This work was financially supported by grant No. OG-93124 from the vice chancellor for research affairs of Ahvaz Jundishapur University of Medical Sciences (AJUMS), Ahvaz, Iran.

\section{References}

1. Moro P, Schantz PM. Echinococcosis: a review. Int J Infect Dis. 2009;13(2):125-33. doi: 10.1016/j.ijid.2008.03.037. [PubMed: 18938096].

2. Eckert J, Deplazes P. Biological, epidemiological, and clinical aspects of echinococcosis, a zoonosis of increasing concern. Clin Microbiol Rev. 2004;17(1):107-35. [PubMed: 14726458].

3. Smego RJ, Sebanego P. Treatment options for hepatic cystic echinococcosis. Int $J$ Infect Dis. 2005;9(2):69-76. doi: 10.1016/j.ijid.2004.08.001. [PubMed: 15708321].

4. Silva MA, Mirza DF, Bramhall SR, Mayer AD, McMaster P, Buckels JA. Treatment of hydatid disease of the liver. Evaluation of a UK experience. Dig Surg. 2004;21(3):227-33. doi: 10.1159/000079492. [PubMed: 15237256] discussion 233-4.

5. Tsimoyiannis EC, Siakas P, Moutesidou KJ, Karayianni M, Kontoyiannis DS, Gossios KJ. Perioperative benzimidazole therapy in human hydatid liver disease. Int Surg. 1995;80(2):131-3. [PubMed: 8530228].

6. Prousalidis J, Kosmidis C, Anthimidis G, Kapoutzis K, Karamanlis E, Fachantidis E. Postoperative recurrence of cystic hydatidosis. Can J Surg. 2012;55(1):15-20. doi:10.1503/cjs.013010. [PubMed: 21939605].

7. Karabulut K, Ozbalci GS, Kesicioglu T, Tarim IA, Lap G, Kamali Polat A, et al. Long-term outcomes of intraoperative and perioperative albendazole treatment in hepatic hydatidosis: single center experience. Ann Surg Treat Res. 2014;87(2):61-5. doi: 10.4174/astr.2014.87.2.61. [PubMed: 25114884].

8. Marriner SE, Morris DL, Dickson B, Bogan JA. Pharmacokinetics of albendazole in man. Eur J Clin Pharmacol. 1986;30(6):705-8. [PubMed: 3770064]
9. Horton RJ. Albendazole in treatment of human cystic echinococcosis: 12 years of experience. Acta Trop. 1997;64(1-2):79-93. [PubMed 9095290].

10. Eckert J, Pawlowski Z, Dar FK, Vuitton DA, Kem P, Savioli L. Medical aspects of echinococcosis. Parasitol Today. 1995;11(8):273-6.

11. Capan M, Keltner S, Thalhammer F, Winkler S, Jager W, Zeitlinger $M$, et al. Intra-cystic drug concentration of albendazole sulphoxide in patients with Echinococcus granulosus cysts. Am J Trop Med Hyg. 2009;81(4):712-3. doi: 10.4269/ajtmh.2009.09-0234. [PubMed: 19815892].

12. Venkatesan P. Albendazole. J Antimicrob Chemother. 1998;41(2):145-7. [PubMed: 9533454].

13. Brusewitz C, Schendler A, Funke A, Wagner T, Lipp R. Nove poloxamer-based nanoemulsions to enhance the intestinal absorption of active compounds. Int J Pharm. 2007;329(1-2):173-81. doi: 10.1016/j.ijpharm.2006.08.022. [PubMed:16996706].

14. Chan JM, Valencia PM, Zhang L, Langer R, Farokhzad OC. Polymeric nanoparticles for drug delivery. Methods Mol Biol. 2010;624:163-75. doi:10.1007/978-1-60761-609-2_11. [PubMed: 20217595].

15. Pandita D, Ahuja A, Lather V, Benjamin B, Dutta T, Velpandian T, et al. Development of lipid-based nanoparticles for enhancing the oral bioavailability of paclitaxel. AAPS PharmSciTech. 2011;12(2):712-22. doi 10.1208/s12249-011-9636-8. [PubMed: 21637945].

16. Sinha VR, Srivastava S, Goel H, Jindal V. Solid Lipid Nanoparticles (SLN'S)-Trends and Implications in Drug Targeting. Int J of Adv in Pharmac Scie. 2010;1(3)

17. Muller RH, Mader K, Gohla S. Solid lipid nanoparticles (SLN) for controlled drug delivery - a review of the state of the art. Eur J Pharm Biopharm. 2000;50(1):161-77. [PubMed:10840199].

18. Wissing SA, Kayser O, Muller RH. Solid lipid nanoparticles for parenteral drug delivery. Adv Drug Deliv Rev. 2004;56(9):1257-72. doi: 10.1016/j.addr.2003.12.002. [PubMed:15109768].

19. Gokce EH, Korkmaz E, Dellera E, Sandri G, Bonferoni MC, Ozer O. Resveratrol-loaded solid lipid nanoparticles versus nanostructured lipid carriers: evaluation of antioxidant potential for dermal applications. Int J Nanomedicine. 2012;7:1841-50. doi: 10.2147/IJN.S29710. [PubMed: 22605933]

20. Ezzati Nazhad Dolatabadi J, Valizadeh H, Hamishehkar H. Solid Lipid Nanoparticles as Efficient Drug and Gene Delivery Systems: Recent Breakthroughs. Adv Pharm Bull. 2015;5(2):151-9. doi: 10.15171/apb.2015.022. [PubMed: 26236652].

21. Ali Khan A, Mudassir J, Mohtar N, Darwis Y. Advanced drug delivery to the lymphatic system: lipid-based nanoformulations. Int J Nanomedicine. 2013;8:2733-44. doi: 10.2147/IJN.S41521. [PubMed: 23926431].

22. Souto EB, Wissing SA, Barbosa CM, Muller RH. Development of a controlled release formulation based on SLN and NLC for topical clotrimazole delivery. Int J Pharm. 2004;278(1):71-7. doi 10.1016/j.ijpharm.2004.02.032. [PubMed:15158950].

23. Rostami E, Kashanian S, Azandaryani AH, Faramarzi H, Dolatabadi JE, Omidfar K. Drug targeting using solid lipid nanoparticles. Chem Phys Lipids. 2014;181:56-61. doi: 10.1016/j.chemphyslip.2014.03.006. [PubMed: 24717692]

24. Haverla T, Gurtler E, Takac L. [A comparative study of clinical results after 5 years of root canal treatment with calcium hydroxide and with Riebler's paste]. Cesk Stomatol. 1966;66(4):251-6. [PubMed: 5220930].

25. Souto EB, Muller RH. Cosmetic features and applications of lipid nanoparticles (SLN, NLC). Int J Cosmet Sci. 2008;30(3):157-65. doi: 10.1111/j.1468-2494.2008.00433.x. [PubMed: 18452432].

26. de Souza MC, Marchetti JM. Development of albendazole sulfoxideloaded Eudragit microparticles: A potential strategy to improve the drug bioavailability. Adv Powder Technol. 2012;23(6):801-7.

27. Ravichandran R. In vivo pharmacokinetic studies of albendazole nanoparticulate oral formulations for improved bioavailability. Int J Green Nanotechnol Biomed. 2010;2(1):B46-53. 
28. Daniel-Mwambete K, Torrado S, Cuesta-Bandera C, Ponce-Gordo F, Torrado JJ. The effect of solubilization on the oral bioavailability of three benzimidazole carbamate drugs. Int J of Pharm. 2004;272(1):29-36.

29. Patel BD, Modi RV, Thakkar NA, Patel AA, Thakkar PH. Development and characterization of solid lipid nanoparticles for enhancement of oral bioavailability of Raloxifene. J Pharm Bioallied Sci. 2012;4(Suppl 1):S14-6. doi: 10.4103/0975-7406.94121. [PubMed: 23066188].

30. Morris DL, Chinnery JB, Georgiou G, Stamatakis G, Golematis B. Penetration of albendazole sulphoxide into hydatid cysts. Gut. 1987;28(1):75-80. [PubMed:3817589].

31. Truong Cong T, Faivre V, Nguyen TT, Heras H, Pirot F, Walchshofer $\mathrm{N}$, et al. Study on the hydatid cyst membrane: permeation of model molecules and interactions with drug-loaded nanoparticles. Int J Pharm. 2008;353(1-2):223-32. doi: 10.1016/j.ijpharm.2007.11.040. [PubMed: 18201847].

32. Hou D, Xie C, Huang K, Zhu C. The production and characteristics of solid lipid nanoparticles (SLNs). Biomaterials. 2003;24(10):1781-5.

33. Ibrahim WM, AlOmrani AH, Yassin AE. Novel sulpiride-loaded solid lipid nanoparticles with enhanced intestinal permeability. Int $J$ Nanomedicine. 2014;9:129-44. doi: 10.2147/IJN.S54413. [PubMed: 24379671].

34. Yones DA, Taher GA, Ibraheim ZZ. In vitro effects of some herbs used in Egyptian traditional medicine on viability of protoscolices of hydatid cysts. Korean J Parasitol. 2011;49(3):255-63. doi: 10.3347/kjp.2011.49.3.255. [PubMed: 22072825].

35. Verma VC, Gangwar M, Yashpal M, Nath G. Anticestodal activity of endophytic Pestalotiopsis sp. on protoscoleces of hydatid cyst Echinococcus granulosus. Biomed Res Int. 2013;2013:308515. doi: 10.1155/2013/308515. [PubMed: 24063003].

36. Skuhala T, Trkulja V, Runje M, Vukelic D, Desnica B. Albendazolesulphoxide concentrations in plasma and hydatid cyst and prediction of parasitological and clinical outcomes in patients with liver hydatidosis caused by Echinococcus granulosus. Croat Med J 2014;55(2):146-55. [PubMed: 24778101].

37. Brunetti E, Garcia HH, Junghanss T, International Ce Workshop in Lima P. Cystic echinococcosis: chronic, complex, and still neglected. PLoS Negl Trop Dis. 2011;5(7):eee1146. doi:10.1371/journal.pntd.0001146. [PubMed: 21814584].

38. Smyth JD, Barrett NJ. Procedures for testing the viability of human hydatid cysts following surgical removal, especially after chemotherapy. Trans R Soc Trop Med Hyg. 1980;74(5):649-52.

39. Ceballos L, Elissondo C, Moreno L, Dopchiz M, Sanchez Bruni S, Denegri G, et al. Albendazole treatment in cystic echinococcosis: pharmacokinetics and clinical efficacy of two different aqueous formulations. Parasitol Res. 2008;103(2):355-62. doi: 10.1007/s00436-008- 0980-x. [PubMed: 18465143].

40. Evrard B, Chiap P, DeTullio P, Ghalmi F, Piel G, Van Hees T, et al. Oral bioavailability in sheep of albendazole from a suspension and from a solution containing hydroxypropyl- $\beta$-cyclodextrin. J Control Rel. 2002;85(1):45-50.

41. Moghimi SM, Szebeni J. Stealth liposomes and long circulating nanoparticles: critical issues in pharmacokinetics, opsonization and protein-binding properties. Prog Lipid Res. 2003;42(6):463-78.

42. Mukherjee S, Ray S, Thakur RS. Solid lipid nanoparticles: a modern formulation approach in drug delivery system. Indian J Pharm Sci. 2009;71(4):349-58. doi: 10.4103/0250-474X.57282. [PubMed: 20502539].

43. Ahmadnia S, Moazeni M, Mohammadi-Samani S, Oryan A. In vivo evaluation of the efficacy of albendazole sulfoxide and albendazole sulfoxide loaded solid lipid nanoparticles against hydatid cyst. Exp Parasitol. 2013;135(2):314-9. doi: 10.1016/j.exppara.2013.07.017. [PubMed: 23912040].

44. Rohit B, Pal KI. A method to prepare solid lipid nanoparticles with improved entrapment efficiency of hydrophilic drugs. Current Nanoscience. 2013;9(2):211-20.

45. Muller RH, Radtke M, Wissing SA. Nanostructured lipid matrices for improved microencapsulation of drugs. Int J Pharm. 2002;242(12):121-8. [PubMed: 12176234]

46. Jain A, Jain SK. In vitro and cell uptake studies for targeting of ligand anchored nanoparticles for colon tumors. Eur J Pharm Sci. 2008;35(5):404-16. doi: 10.1016/j.ejps.2008.08.008. [PubMed: 18824095].

47. Ezzati Nazhad Dolatabadi J, Omidi Y, Losic D. Carbon nanotubes as an advanced drug and gene delivery nanosystem. Current Nanoscience. 2011;7(3):297-314.

48. Ezzati Nazhad Dolatabadi J, Mashinchian O, Ayoubi B, Jamali AA, Mobed A, Losic D. Optical and electrochemical DNA nanobiosensors. Trac-Trend Anal Chem. 2011(30):459-72.

49. Saei AA, Dolatabadi Ezzati Nazhad J, Najafi-Marandi P, Abhari A, de la Guardia M. Electrochemical biosensors for glucose based on metal nanoparticles. TRAC-Trend Anal Chem. 2013;42:216-27.

50. Perez-Serrano J, Denegri G, Casado N, Rodriguez-Caabeiro F. In vivo effect of oral albendazole and albendazole sulphoxide on development of secondary echinococcosis in mice. Int J Parasitol. 1997;27(11):1341-5. [PubMed: 9421721].

51. Lanusse CE, Virkel GL, Sanchez SF, Alvarez LI, Lifschitz AL, Imperiale F, et al. Ricobendazole kinetics and availability following subcutaneous administration of a novel injectable formulation to calves. Res Vet. 1998;65(1):5-10. 